\title{
Issues and Problems of Community Water Supply Schemes with Special Reference to Nepal
}

\author{
Gunjan Gautam*, Khet Raj Dahal \\ Lumbini International Academy of Science and Technology, Lalitpur, Nepal \\ Email address: \\ er.gunjangautam@gmail.com (G. Gautam),krdahal@liast.edu.np (K. R. Dahal) \\ ${ }^{*}$ Corresponding author
}

\section{To cite this article:}

Gunjan Gautam, Khet Raj Dahal. Issues and Problems of Community Water Supply Schemes with Special Reference to Nepal. Journal of Civil, Construction and Environmental Engineering. Vol. 5, No. 5, 2020, pp. 114-125. doi: 10.11648/j.jccee.20200505.13

Received: September 1, 2020; Accepted: September 17, 2020; Published: September 23, 2020

\begin{abstract}
Drinking water is a basic need for survival and good health of human beings as well as for any form of life on earth. In the absence of potable water, there is a high risk of transmission of serious diseases among people, like diarrhea, dysentery, cholera, and typhoid. Despite significant progress on community water schemes, worldwide still 2.2 billion people are out of access to safely managed water services. This study was conducted during the period from February to July 2020 . Published literature such as paper, thesis, manuals, database, reports, and standards were collected from different sources and went on thoroughly. The conclusions are drawn based on studied materials. The study found that about 829 thousand people are estimated to die each year from diarrhea because of unsafe contaminated drinking water, sanitation, and hand hygiene. In South Asia, over 134 million people still do not have access to clean drinking water. Various studies have shown that progress on basic water supply in Nepal has reached up to $89 \%$ of the population by the end of 2019. Community drinking water schemes in Nepal are facing various types of problems, such as technical problems related to, gender equity and social inclusion (GESI), cost recovery and affordability, operation and maintenance, institutional, and legal framework. Because those problems on water schemes are not timely and appropriately addressed, there is always a high impact on un-functionality, poor service, and unsustainability. The study would like to suggest that the operation and maintenance funds should be managed after the implementation of the project. The capacity building training for the water users committee should be conducted before the handover of the schemes.
\end{abstract}

Keywords: Community Water Supply Scheme, Operation and Maintenance (O\&M), Functionality, Water, Sanitation and Hygiene (WASH), Construction

\section{Introduction}

Clean water with hygienic sanitation is an essential component for the wellbeing of dignified healthy life of human beings, their economic development, and it is also the basic requirement of well-functioning of the world's ecosystem. Drinking water services stand for the ease of access, availability, and quality of the main source used by households for drinking, cooking, personal hygiene, and other domestic uses [1]. The right to water and sanitation is a crucial aspect of the struggle to improve this situation. The provision of safe water supply and improved sanitation to the rural community has been a major challenge to the national and local governments in the world and more particularly in developing regions [2].

Despite significant progress in basic service level water and sanitation in Nepal, the government's commitment to provide universal access to water and sanitation to all by 2017 was achieved $89 \%$ only due to various problems like the Gorkha earthquake, landslides, terai flood, and other problems during this period. However, Nepal was declared open defecation free (ODF) country on 30th September 2019 [3] which is one of the remarkable achievements on the sanitation part. As drinking water and sanitation facilities are basic needs for human beings, the provision of providing safe drinking water and sanitation facility has been still kept in high priority of Government of Nepal through $15^{\text {th }}$ periodic plan [6]. Commitment to provide basic service level water supply and sanitation to the citizen of Nepal from government level was started through various plan and policies such as National water plan 2005, various five-year periodic plan, Rural water supply and sanitation national policy 2004, Rural water supply 
and sanitation national strategy 2004, approach paper of Ministry of urban development 2012. Similarly, the Constitution of Nepal 2015 [4], Article 35 (4) has recognized that access to safe water and sanitation facilities as fundamental rights of the people.

Based on the latest report, over 600 million people do not have access to even a basic level of drinking water \& one billion people still practice open defecation in the world. To fulfill this huge necessity of WASH, Sustainable Development Goal 6 has aimed to ensure access to water and sanitation for all by 2030 [5]. In Nepal, till the end of $14^{\text {th }}$ periodic plan i.e. 2019 of National planning commission (NPC), 89\% of the country population has accessibility on basic drinking water services, $21 \%$ population has been benefitting from medium and higher level drinking water service and $99 \%$ population has access to sanitation services [6]. The joint response of multiple sectorial actions can reduce vulnerability and maintains water sources, safe waste management systems, which ensures WASH, which is a priority action in the response to emergencies [7]. Thus, water, sanitation, and hygiene (WASH) is lifesaving intervention as usual in daily life and emergency context.

\section{Main Body of the Study}

Community-based water management is an indispensable component of managing freshwater scarcities in almost everywhere in the world. The rural water supply and sanitation project in Nepal involves local communities in planning and operating rural water schemes, promoting awareness of the benefits of environmentally sound sanitation [8].

Nonetheless, the experience of rural water supply and sanitation services in Nepal reiterates lack of access in management and technical skills and materials resulting in poor management by water users committee of operation, resource mobilization as a major problem concerning commonly managed rural water supply and sanitation schemes [10]. Equitable access to water supply and sanitation services is another key issue, particularly in remote areas [12].

With the aim of providing water supply facilities to every citizen, the department of water supply and sewerage was formed in 1972 as a leading government agency for water supply and sanitation. Since then rural water supply schemes have been implemented in Nepal through public sectors. Besides DWSSM, there are other several I/NGOs, which are supporting the local government for establishing community water supply and sanitation schemes. Once construction of water supply and sanitation scheme is completed, as per the Government of Nepal policy those completed water schemes have to be handed over local Water Users' and Sanitation Committee (WUSC), expecting that the project will be functional \& sustainable if it is managed (i.e. is operated and maintained) by the community which increases ownership feeling of community and reduce the Government's administration expenditures [9].

\subsection{Operation and Maintenance of Community Water Supply Schemes}

Appropriate operation and maintenance can reduce the wastage of water due to human activities, damage due to natural disasters such as landslide, flood, and wildfire. Thus, all of these impose the importance of efficient and proper management with disaster risk reduction intervention of water supply schemes.

Similarly, by analyzing the five-year periodic plan of government of Nepal, data reflects that, till the ninth five-year plan (1997-2002) period, the majority of water supply schemes were constructed giving importance on the quantity of water to be supplied to community and less priority were given on water quality approach. After launching the national drinking water quality standards [12] Government of Nepal's policy has focused on improved quality of drinking water in community water schemes. In rural areas, the functionality of constructed water supply has been one of major problems. As per the report published by National Management Information Project (NMIP) of DWSS, in 2014, out of the total number of completed schemes, $61.5 \%$ were functioning well including the schemes need a minor repair, likewise, $38.5 \%$ of nonfunctional schemes, $9.2 \%$ of water scheme were requiring major repair, requiring major rehabilitation program was $19.8 \%$, schemes requiring reconstruction was $8.6 \%$ and $0.9 \%$ non-functional [10].

Post disaster need assessment (PDNA) data reflects that in the Gorkha earthquake 2015, out of a total 11,288 water supply schemes in the 14 most-affected districts, 1,570 systems suffered from major damages, 3,663 partial damages [14]. Therefore, a lack of disaster risk reduction in the water supply is still one of the major problems.

To reduce the percentage of schemes requiring the major repairs, rehabilitation, reconstruction there is a high need for appropriate action on disaster preparedness, awareness in the community, managing adequate funds for regular operation $\&$ maintenance.

Sindhupalchowk district is a massively disaster-affected district of Nepal by several natural disasters like the Gorkha earthquake 2015, Jure landslide [11]. In this district, the study of major problems associated with water supply schemes has not studied in the aspect of functionality, disaster preparedness, consumer satisfaction. However, a similar nature study has been carried out in other districts. The status of the regions affected by the earthquake is different than in other regions. Thus, this study was necessitated to be carried out for study on the major problem associated with community water supply schemes of such disaster impacted district like Sindhupalchowk because of following reason;

1) Direct negative impact was seen in human health due to disaster,

2) Property loss, loss in WASH infrastructure due to the disaster directly impacted on the functionality of drinking water supply scheme,

3) Contamination of flood into spring source can create water pollution and causes diarrheal disease, waterborne diseases, and loss of life. 
A literature review is a widespread summary of previous research on a relevant area of research [12]. The literature review in this study gives an understanding of community drinking water supply schemes. Clean water is a basic need for survival \& good health of human beings as well as for any form of life on earth. In the absence of safe drinking water, the possibility of life is nonexistent. The water people drink and use for other purposes is clean water, which means water must be free of germs, chemicals and must be clear, not cloudy. Water is safe for drinking known as potable water [13].

Safe drinking water has a direct relationship with human health and sanitation. Contaminated water and poor sanitation have a direct relationship with the transmission of serious diseases like diarrhea, dysentery, cholera, typhoid and many more [14]. Besides, poorly managed water and sanitation services makes individuals vulnerable to health risks whereas well- managed water supply scheme which comes from improved and accessible sources nearby community can save their time and physical effort for fetching safe water. Individuals can use this saved time on something productive.

Systematic development of the water supply scheme in the community can provide a positive contribution to the social and economic development of the country and this can also create a favorable impact on the improvement of the healthy environment of the citizens. The United Nations (UN) as well as the constitution of Nepal 2015 [4], has declared that access to clean water and sanitation as a fundamental human right. Therefore, the government is dedicated to providing a basic level of water supply facilities to all citizens and has regularly prioritizing on the periodic development plan. Government of Nepal was targeting to reach the set goal of providing basic level water and sanitation service to $100 \%$ citizens of Nepal by 2017 [15]. However, this target was not reached on the predefined timeline due to various problems and till the end of $14^{\text {th }}$ periodic plan of National planning commission (NPC) of Nepal, $89 \%$ of the country population has accessibility on basic drinking water services, $21 \%$ population has benefited from medium and higher level drinking water service and $99 \%$ population has access on basic level sanitation services [6]. Similarly in the sanitation part, it was a great achievement that Nepal has declared open defecation free (ODF) nation on $30^{\text {th }}$ September 2019. and moving towards total sanitation [16].

\subsection{Classification of Community Water Supply Schemes}

Community water supply schemes can be classified in many ways among which following types are described below;

\subsubsection{Classification Based on Water Sources}

Community Water supply can be classified based on the type of water sources and technology used, which are groundwater, surface water, and rainwater system. The type of water supply technology to be selected can depend on the hydro-geological conditions, the existing situation, the resources available to the program, and the willingness of the community to contribute [17].

\subsubsection{Classification Based on Service Area of Water Supply Schemes}

In Nepal several policies on water supply has categorized two types of water supply schemes which are;

i. Rural Water Supply Scheme

Water supply schemes constructed for the rural community is known as a rural water supply scheme. Generally, population coverage of each rural water supply is less than urban areas. The government of Nepal has formulated rural water supply and strategy 2004 with special consideration of rural water service facilities.

ii. Urban Water Supply Scheme

Water supply schemes constructed for the urban community or city is known as urban water supply scheme. Generally, population coverage of each urban water supply is higher than in rural areas. The government of Nepal has formulated national urban water supply and sanitation sector policy 2009 targeting for service delivery in the urban population.

\subsubsection{Classification Based on Use of Water}

Based on the use of water in the community, the water supply scheme can be divided into two categories which are (i) single-use domestic water system and (ii) multiple-use water system (MUS) [18].

i. Single Use Domestic Water System (SUS)

This type of water supply scheme is a conventional domestic water system that meets the basic needs of household use for drinking, cooking, washing, and bathing. In Nepal, single-use domestic water supply scheme is widely implemented to expand universal coverage of water supply throughout the nation, considering project cost. This single-use water system can save the cost of constructing a reservoir tank as this system design consider water demand 45 liters per capita per day (Lpcd) to $100 \mathrm{Lpcd}$ [19] based on the availability of discharge on the water source.

This type of water supply scheme consists of several structures such as intake at the water source, valve chamber, collection chamber, transmission pipeline, water storage reservoir tank, distribution pipelines, air valve chamber, washout chambers, public, or household water tap stand.

ii. Multiple Use Water System (MUS)

When water supply facilities provide services for drinking, household use, and small irrigation like drip irrigation or micro-sprinkler irrigation for small farmers, it is known as a multiple-use water system (MUS). The basic structures of this type of water system are the same as the single-use domestic water supply scheme. However, water reservoir tank capacity, main transmission pipeline, and distribution pipeline are bigger in comparison to SUS. In this system, water is collected from the gravity flow system from spring or stream source at elevated land or hills into a reservoir tank and supplied through distribution pipelines for public tap stand or household tap and irrigation takeoff pipelines [20].

\subsubsection{Classification Based on System Coverage}

Nepal WaSH sector development plan (2016-2030) prepared by the ministry of water supply and sanitation has 
classified water schemes in four categories [21], which are;

i) Point water system: Example; Kuwa, Panera, one tap, hand pump.

ii) Small water supply scheme: Water supply scheme which has less than 50 taps,

iii) Medium water supply: Water supply scheme which has up to 1000 taps,

iv) Large water supply: Water supply scheme which has above 1000 taps to 4000 taps.

\subsection{Treatment in Water Supply Schemes}

The health effects of poorly managed water and sanitation facilities include an estimated four billion cases of diarrhea and 1.9 million deaths every year, commonly between young children in developing countries [22].

\subsubsection{Centralized or Community Water Treatment}

Water can be treated at a reservoir tank in large volumes then distributed to households from distribution pipelines. This technique is known as centralized or community water treatment [23]. Around the several centralized water treatments technologies which need to be chosen for implementation based on the condition of water quality to be treated and design, some of those techniques are screening and aeration, sedimentation, coagulation and flocculation, clarification, slow sand filter, rapid sand filter, disinfection by physical method i.e. boiling and sunlight, disinfection by chemical dosing method e.g. chlorination, water softening, etc. [24].

\subsubsection{Household Water Treatment and Safe Water Storage in Households}

Smaller volumes of water can also be treated at the point of use (POU), such as in a home. This is commonly called household water treatment and safe storage (HWTS) since the family members collect the water and then treat and store it in their homes. For example, candle filter, bio-sand filter, boiling, solar disinfection (SODIS), sedimentation, etc. are some of the household water treatment techniques [23].

POU or point of entry water treatment system in which point of entry treatment technology device for example Activated alumina (AA), Distillation, Granular activated carbon, Anion exchange (AX), Cation exchange (CX), Reverse osmosis (RO), etc. is installed at household pipe connection just before water enters at the house [25].

Safe storage and usage of water can decrease this health problem meaningfully, similarly all of the storage systems in households for example cans, covered buckets, or reservoir water tanks in the community must be cleaned and checked frequently to avoid health risks or harms [26].

Keeping treated water apart from the probable source of contamination by using a clean and covered container is known as the safe storage of water. Also while drinking water, the clean container should be used so that people do not make sick each other [27].

\subsection{Disaster Risk Reduction in Water Supply Schemes}

Disaster is a serious disturbance of the operation of a community involving extensive human, material, economic or environmental losses and impacts, which exceeds the ability of the affected community or society to cope using its resources [28].

For example, in the Gorkha earthquake 2015, there was a great loss in the water and sanitation sector in Nepal. Postdisaster need assessment finding shared by the government of Nepal was estimated that there was the net total value of NPR 11.4 billion at pre-disaster prices, of which NPR 10.5 billion related to infrastructure and physical assets damage and losses in water and sanitation sector [29], further this sector assessment finding has presented that out of a total 11,288 water supply schemes in the 14 most-affected affected districts from Gorkha earthquake, 1,570 systems suffered from major damages, 3,663 partial damages. Likewise, out of the total 16,433 water supply schemes in the 17 moderately affected districts, 747 systems suffered from major damage, 1,761 were partially damaged. This example of great losses of community water supply schemes reveals that there is always a need for disaster risk reduction in the water and sanitation sector.

\subsubsection{Disaster Management Cycle}

Figure (Figure 1) presented hereunder is the disaster management cycle. This disaster management cycle involves the pre-disaster phase and post-disaster phase activities. The pre-disaster phase consists of prevention, mitigation, and preparedness, which is also known as disaster risk reduction (DRR), on which capacity building activities, possible structural and nonstructural prevention, mitigation measures are adopted. Similarly, after the disaster event occurred, there are response activities in the emergency stage and recovery phase which consist of restoration and reconstruction activities.

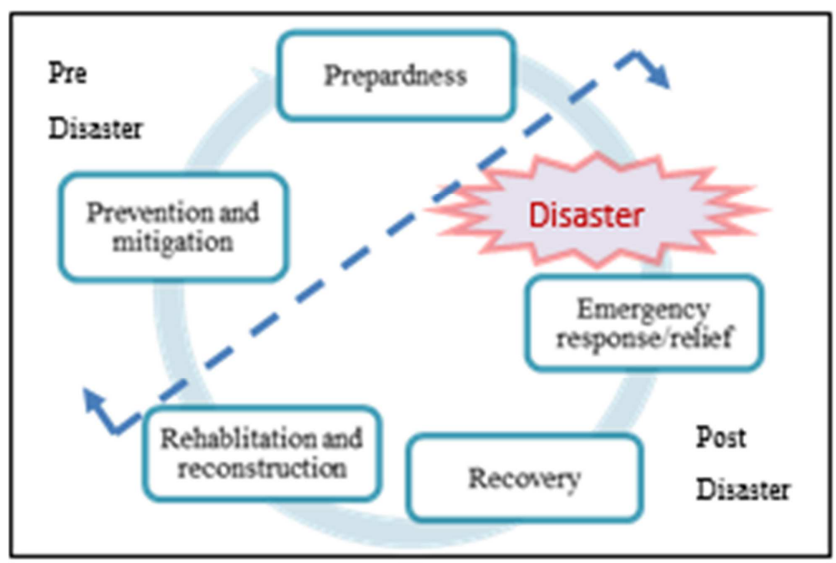

Figure 1. Disaster Management cycle.

\subsubsection{Water Safety Plan (WSP)}

The WHO Guidelines for Drinking-water Quality consider WSPs as one of the key components of the preventive management structure for safe drinking water. WSPs are suggested as the best methodology for assuring the security of drinking-water supplies to consumers with good and consistent quality. WSPs are planned on the guideline of Hazards Analysis and Critical Control Points (HACCP) and dependent on Multi Barrier Approach. In Nepal, WSPs have been steered since 2006, 
with WHO support [30]. WSP is important for giving a preventive measure of disaster risk management framework in water schemes and mitigating public health-related hazards in usual working conditions and emergency circumstances.

Water safety plan is a widespread hazard evaluation and risk management approach that includes all means in a drinking-water distribution chain of water schemes, from catchment to consumer [31].

Rural water supply and sanitation project-western Nepal (RWSSP-WN) has prepared different water safety plan guidelines for lift water supply schemes and gravity water supply schemes to guide Water users and sanitation committees (WUSC) and their water safety planning facilitators. WSP concept combines the Water safety plan with the regular operation \& maintenance $(\mathrm{O} \& \mathrm{M})$ plan and water tariff collection. It also pays attention to climate change adaptation \& disaster risk reduction [32].

Water safety plan consists of generally six to ten steps as per WHO and national guidelines, which are 1) Water safety team the formation, 2) Water supply system analysis, 3) Hazard identification and analysis, 4) Identification of control measures, 5) System improvement, 6) Regular monitoring plan, 7) Validation and control, 8) Regular verification, 9) User satisfaction, 10) Documentation of water safety plan.

\subsection{Global Problem and Responses in Community Water Supply \& Sanitation}

About 71 percent of the Earth's surface is covered in water, among the available water on the earth however, freshwater is only $2.5 \%$. Among $2.5 \%$ of freshwater $68.7 \%$ under glacier and ice cap, $30.1 \%$ is underground, remaining surface and other freshwater is $1.2 \%$. Among $1.2 \%$ of surface water, $69 \%$ is ice and permafrost, $20.9 \%$ is on lakes, $3 \%$ is on atmosphere, $3.8 \%$ is soil moisture, $2.6 \%$ is swamp, marshes, $0.49 \%$ is rivers, and $0.26 \%$ is on living things [33]. Thus, the above information from USCG is helpful to elaborate on how much is inaccessible to supply safe and portable water to the human community and living beings within limited freshwater in the world.

Up to 2017 , about 5.3 billion population coverage was reached through a safely managed drinking water supply scheme, which is improved water sources located nearby their premises, available whenever needed, and free from contamination [14]. Further, it states that remaining 2.2 billion people are out of access to safely manage water services which include 1.4 billion people with basic water supply services, which means improved water source located within a round trip of 30 minutes to fetch water, 206 million people with limited services or an improved water source which requires more than 30 minutes to fetch water, 435 million people using unprotected wells an springs, 144 million people collecting water from untreated surface water, for example, lakes, rivers, ponds, and streams.

Climate change impacts, rising water scarcity day by day with population growth, demographic changes and urbanization has created problems on water supply schemes. About 4 billion people are facing the problem of severe water scarcity at least one month every year. Over the last century, global water use pattern has increased with water demand at more than twice the rate of population growth [34].

When a safely managed water supply scheme is absent, there is always the chance of increasing vulnerability to the individual from preventable health risks. Inadequate management of wastewater produced from industries, urban areas, and agricultural activities creates drinking water solution pollution. Study shows that in worldwide about eight hundred twenty-nine thousand people are estimated to die each year [14], and one thousand children under the age of five die every day [35] from diarrhea because of unsafe drinking water, poor sanitation, and improper hand hygiene.

As the major global response on water supply \& sanitation schemes, Sustainable Development Goal (SDG) global goal 6 aims to 'Ensure availability and sustainable management of water and sanitation for all' and this SGD Goal 6 further contains six technical targets related to water, sanitation, and hygiene, water efficiency, wastewater management, integrated water resource management \& protection of aquatic ecosystems. Among targets 6 numbers of SDG goal 6, target 6.1: which states that "by 2030, achieve universal and equitable access to safe and affordable drinking water for all" [38]. This means $100 \%$ of the world population will have access to safe and affordable drinking water without any discrimination because of race, ethnicity, and locality of people by 2030. Monitoring target 6.1 further requires going beyond the household and considering access in institutional settings and public spaces, such as schools $\&$ health care facilities.

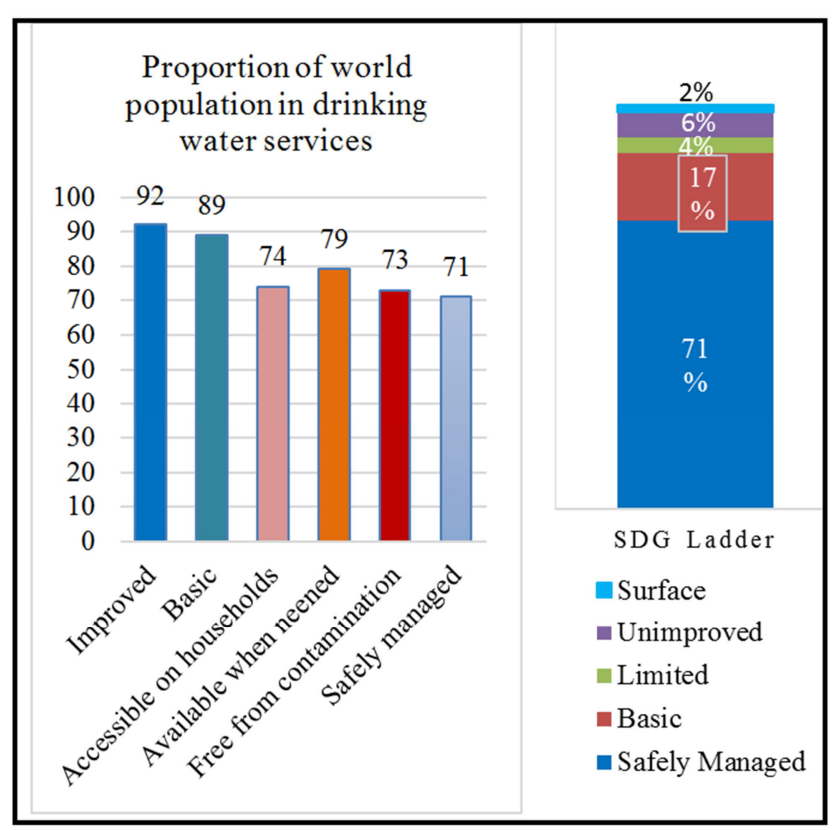

Figure 2. SDG baseline estimates for drinking water services from the JMP 2017 report [1].

As presented on the figure (Figure 2) hereunder, baseline report for SDG prepared by JMP on 2017, estimates that proportion of the global population with drinking services who have access on improved service is $92 \%$, similarly, $89 \%$ basic, accessible on-premises $74 \%$, available when needed $79 \%$, free from contamination $73 \%$, safely managed $71 \%$. Similarly, while comparing the proportion of the global population on the SDG 
ladder for drinking water service, $71 \%$ have safely managed service, $17 \%$ basic service, $4 \%$ limited, $6 \%$ unimproved, and $2 \%$ still using directly surface water like river, pond \& stream.

Figure (Figure 2) presented below describes the proportion of the world population in drinking water services.

The WHO/UNICEF Joint Monitoring Program for Water Supply and Sanitation (JMP) was established in 1990. JMP has a provided special note on defining the improved drinking water sources, those that have the potential to deliver safe water by nature of their design and construction, and include: piped water, boreholes or tube wells, protected dug wells, protected springs, rainwater, and packaged or delivered water.

The JMP has developed a new service ladder to facilitate enhanced monitoring of drinking water during the SDG era (2016-2030) as presented on table (Table 1) hereunder;

A Joint monitoring plan has classified and defined the household service ladder for drinking water supply.

Table 1. JMP service ladder for household drinking water [36].

\begin{tabular}{ll}
\hline Service Level & Defination \\
\hline Safely Managed & $\begin{array}{l}\text { Drinking water from an improved water source which is located on permises, available when needed and free of fecal and priority } \\
\text { chemical contimination }\end{array}$ \\
Basic & Drinking water from and improved source provided collection time is not more than 30 minutes for a round trip including queing \\
Limited & Drinking water from and improved source where collection time exceeds over 30 minutes for a roundtrip to collect water, including queing \\
Unimproved & Drinking water from an unprotected dug well or unprotected spring \\
No service / Surface & Drinking water collected directly from a river, dam, lake, pond, stream, canal or irrigation cannel \\
\hline
\end{tabular}

The report published by WHO in 2009, named Vision 2030 -the resilience of water supply and sanitation in the face of climate change, which had predicted that climate change will increase \& overpressure on community management water schemes. This had predicted that about $57 \%$ of rural households will be collecting water from community sources such as tube wells, protected wells, boreholes, and protected springs in 2020 [37]. While reaching in 2020 , the prediction still came valid \& we can found overstress on drinking water sources, with an increase in climate change impact.

\subsection{Regional Problem and Response in South Asia on Community Water and Sanitation}

Despite considerable progress in access to water and sanitation services, there is too much remains to be done. In South Asia, access to improved water increased from 73 percent to 93 percent since 1990 . However, over one hundred thirty-four million humans still do not have access to improved safe water. It is currently predicted that in South Asia between sixty-eight to eighty-four percent of water sources are contaminated. Similarly, 610 million people in South Asia still practice open defecation [38].

Analysis of International Benchmarking Network (IBNET) for Water and Sanitation Utilities data across South Asia and South-East Asia shows that majority of countries have average continuity of service is less than 24 hours per day. The situation is most acute in Bangladesh, India, and Nepal which each have an average continuity of service of fewer than 10 hours a day [39].

Similarly, South Asia is more vulnerable to natural and manmade disasters. Natural hazards like a landslide, flood, cyclone, drought, earthquakes create a direct impact on millions of individuals including a most vulnerable group of people like children, elderly people, etc. Inadequate conditions of drinking water, sanitation, and hygiene practices create the worse condition for disaster-affected people causing waterborne diseases [38].

\subsection{Situation of Community Water and Sanitation in Nepal}

Nepal has under $0.4 \%$ of the total population however $2.3 \%$ of the world's water resources can be found in this country [40]. Despite the rich in water source as assets, in any case, the nation's difficult landscape of Nepal makes access to water supply hard for many areas.

Nepal suffers a loss of about 1000 people's lives every year due to natural hazards, and a direct loss of an average of nearly 1208 million Nepali rupees per year. Every year millions of national and international expenditures are spent on disaster response activities, which absorbed a plenty of resources that would normally be allocated for well-grounded national development efforts [41].

Due to various natural and men made disasters, the impact on water source depletion has caused a reduction in access to water. Therefore, water services have not been able to become safe, reliable, and sustainable. Similarly, due to increased pressure on human settlement development and expansion, human activities and unmanaged sanitation services has made water sources and environment more polluted [6].

Planned development of public water and sanitation system was started in Nepal since the Government of Nepal (GoN) were initiated the first-five year periodic plan of 1956-1961. Initially, water supply activities were implemented through the Department of Irrigation for a long time until the establishment of the Department of Water Supply and Sewerage (DWSS) in 1972 [42]. After establishment DWSS, this department is leading the development of water supply programs all over the country.

As per the report published by Government of Nepal, Ministry of Water Supply and Sanitation (MoSS), all of the districts have water supply coverage above $70 \%$, nineteen districts have coverage of more than $90 \%, 41$ districts between $80-90 \%$ and 14 districts below 80\%, Rupandehi, Manang, and Kailali reported nearly $100 \%$ coverage.

Thus, in Nepal over the last two decades, access to basic drinking water has increased remarkably from $68 \%$ in 2000 to $89 \%$ in 2019 (Figure 3 ) however the coverage of quality safe 
water as per standard remained only $21 \%$ in 2019 , which is very low [46].

To maintain quality of safe drinking water services, every project/scheme needs to focus to empower the communities for their participation in all stages of the project implementation i.e. planning, implementation, operation and maintenance, monitoring and evaluation of the schemes, which only can ensure the functionality and sustainability of the schemes. In the last ten years, there has been a change in the way that risk is perceived and community-managed in the drinking water supply. Accordingly, the Government of Nepal was preparing Sanitation and Hygiene Master Plan (2011) focusing on total sanitation and Open Defecation Free society targeting to achieve by 2017, however country reached ODF only in 2019 [45]. Similarly, as per plan, national target for universal coverage on water supply and sanitation by 2017 was not reached on time due to several constraints, natural disaster like the Gorkha earthquake in 2015, Nepal flood 2017, etc.

The trend of water supply coverage in Nepal is presented in Figure (Figure 3) hereunder.

While comparing trends among the coverage of water supply and sanitation, in the initial phase, the priority was given to water supply rather than sanitation component. From the above figure, it is clear that the coverage of sanitation up to 2000 was very slow and even if up to 2010 the sanitation coverage was only $43 \%$ however the coverage of basic water supply was $80 \%$. But after the approval and implementation of Sanitation and Hygiene Master Plan 2011, the basic sanitation coverage increases vastly up to $99 \%$ by 2019 whereas progress on basic water supply was reached up to $89 \%$ only till the end of 2019 .

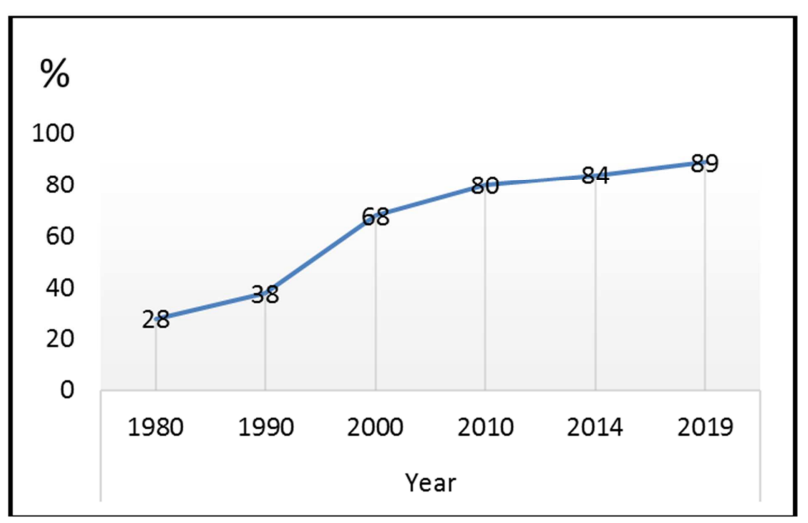

Figure 3. Trend of water supply coverage in Nepal Source: [4]/[15].

Ensure availability and sustainable management of water and sanitation for all. Table (Table 2) presented hereunder is Nepal government proposed indicators and targets for sustainable development goal (SDG)-6.

Table 2. Nepal Government proposed indicator for SDG 6.

\begin{tabular}{|c|c|c|c|c|c|c|}
\hline \multicolumn{7}{|l|}{ Targets with proposed indicators, current status and future projection } \\
\hline Targets and Indicators & 2014 & 2017 & 2020 & 2022 & 2025 & 2030 \\
\hline \multicolumn{7}{|c|}{ Target 6.1 By 2030, achieve universal and equitable access to safe and affordable drinking water for all } \\
\hline 6.1 a Households with access to piped water supply $(\%)$ & 49.5 & 58 & 66.6 & 72.3 & 80.8 & 95 \\
\hline $6.1 \mathrm{~b}$ Basic water supply coverage $(\%)$ & 83.6 & 86.5 & 89.4 & 91.3 & 94.2 & 99 \\
\hline $\begin{array}{l}\text { 6.1c Households with Escherichia coli (E.coli) risk level in household water }>=1 \text { colony } \\
\text { forming unit (cfu) } / 100 \mathrm{ml}(\%)\end{array}$ & 82.2 & 66.8 & 51.4 & 41.1 & 25.7 & 0 \\
\hline 6.1d Households with E.coli risk levels in source $>=1 \mathrm{cfu} / 100 \mathrm{ml}(\%)$ & 71.1 & 57.8 & 44.4 & 35.6 & 22.2 & 0 \\
\hline
\end{tabular}

Source: [43].

In the ninth five-year periodic plan of the Government of Nepal, water supply service level was classified based on quantity, quality, accessibility, continuity, and reliability as presented on the table (Table 3 )

Table 3. Water supply service standards

\begin{tabular}{llll}
\hline Particulars & High & Medium & Basic \\
\hline Quantity (LPCD) & $112-150$ & 65 & $20-45$ \\
Quality & WHO Guideline & National Standards & Potable \\
Accessibility & Within the house (fully & Within the compound (Yard tap) & Within the 20 minutes walking distance \\
Duration of Supply (Hrs./Day) & plumbed) & & (Stand post supply) \\
Continuity (Month/Year) & 24 & 24 & $2-4$ \\
\hline
\end{tabular}

Source: [19].

Appropriate management of all water supply schemes can only be ensured when the delivery of safe drinking water meets the service level presented on the table (Table 3) set by Government of Nepal.

A study has found that water supply schemes implementing agencies are still doing very limited works for quality assurance, like water quality and sanitary surveillance. In this aspect, the approved National Drinking Water Quality Standard (NDWQS), emphasizes the provision of quality water must be maintained as per national standard to the end-user in a phase-wise manner, which is only possible through the application of proper quality assurance mechanism in addition to the provision of the treatment system. 
Basic level water supply and sanitation coverage in seven province of Nepal is presented on table (Table 4).

Table 4. Basic level water supply and sanitation coverage in seven provinces of Nepal.

\begin{tabular}{lll}
\hline Province & Water Supply \% & Sanitation \% \\
\hline Province One & 85.55 & 98.28 \\
Province Two & 87.86 & 89 \\
Bagmati & 91.01 & 98.46 \\
Gandaki & 89.68 & 100 \\
Province 5 & 88.2 & 99.17 \\
Karnali & 70.45 & 100 \\
Sudurpakshim & 87.39 & 100 \\
Nepal & 87.39 & 96.3 \\
\hline
\end{tabular}

Source: [44].

As per survey data of DWSSM published in 2018, on basic level water supply and sanitation coverage in seven provinces of Nepal, highest level water supply coverage was 91.01\% in Bagmati province and lowest level water coverage was $70.45 \%$ in Karnali province. Similarly, the lowest level of sanitation coverage was $89 \%$ in province two [44]. In 2018, national wide coverage of water supply was $87.39 \%$ and national coverage of sanitation was $96.3 \%$. However, this water supply and sanitation coverage was increased in 2019 and Nepal was declared open defecation free nation 2019.

\subsection{Situation of Community Water and Sanitation in Sindhupalchowk}

In Sindhupalchowk district, basic level water supply coverage was $80.9 \%$ in 2010 , this coverage was increased in 2012 and reached $80.4 \%$. In 2014 water supply coverage was reached $86.41 \%$. Similarly, in comparison to water supply coverage sanitation coverage was very less i.e. $33.8 \%$ in 2010 , up to 2012 progress in sanitation coverage was very slow and reached only $38.2 \%$. This sanitation coverage was vastly increased and reached $93 \%$ in 2014 [46].

Table (Table 5) presented hereunder is water and sanitation coverage in Sindhupalchowk district.

Table 5. Water and Sanitation Coverage in Sindhupalchowk district.

\begin{tabular}{|c|c|c|c|c|c|c|c|c|c|c|}
\hline 2010 & & & & 2012 & & & & 2014 & & \\
\hline Water & Sanitation & Projected Population & Total HH & Water & & Sanitation & & Water & Sanitation & Projected Population \\
\hline$\%$ & $\%$ & & HH & HH & $\%$ & HH & $\%$ & $\%$ & $\%$ & \\
\hline 80.9 & 33.8 & 360,578 & 62111 & 52,237 & 84.2 & 236,885 & 38.2 & 86.41 & 93 & 284,695 \\
\hline
\end{tabular}

Source: [15].

In the selected study area i.e. Chautara-Sangachokgadi municipality, Sindhupalchowk 9699 households (HH) family have been benefited from the piped water supply scheme. This piped water supply coverage of this municipality is $88.93 \%$. Table (Table 6) presented hereunder dependent family numbers and coverage \% by various sources of drinking water supply in Chautara-Sangachowk Municipality, Sindhupalchowk.

Table 6. Dependent family household (HH) numbers \& \% on various water sources of drinking water supply in Chautara-Sangachowkgadi municipality, Sindhupalchowk.

\begin{tabular}{|c|c|c|c|c|c|c|c|c|c|c|c|c|c|c|}
\hline \multirow{2}{*}{ S. N. } & \multirow{2}{*}{ Local Level } & \multicolumn{2}{|l|}{ Pipe } & \multirow{2}{*}{$\begin{array}{l}\text { Tube well } \\
\text { HH }\end{array}$} & \multirow{2}{*}{$\begin{array}{l}\text { Covered Well } \\
\text { HH }\end{array}$} & \multirow{2}{*}{$\%$} & \multicolumn{2}{|c|}{ Open well } & \multicolumn{2}{|c|}{ Spring tap } & \multicolumn{2}{|c|}{ River/ stream } & \multirow{2}{*}{$\begin{array}{l}\text { Other } \\
\text { HH }\end{array}$} & \multirow{2}{*}{$\begin{array}{l}\text { Not defined } \\
\text { HН } \\
\end{array}$} \\
\hline & & HH & $\%$ & & & & HH & $\%$ & НH & $\%$ & HH & $\%$ & & \\
\hline 1 & Chautara Sangachowkgadi & 9699 & 88.93 & 1 & 235 & 2.15 & 145 & 1.33 & 708 & 6.49 & 7 & 0.06 & 6 & 105 \\
\hline
\end{tabular}

Source: Sindhupalchowk District Profile, 2075.

\subsection{Community Water Supply Schemes}

Community water supply schemes are those systems in which community people are in the frontline during scheme selection, scheme design with the support of engineers, during construction, and post-construction phase. The water supply scheme is constructed for the community, fulfills the user water demand by quantity and standards, it should be accessible, reliable for the whole year with safe water quality, these factors increase the user's satisfaction. Once the construction is completed, the water scheme is handover to community so that the community ownership would increase with operation and maintenance responsibility. Concept of community water supply scheme is demand-driven system, considering sustainable functionality of water schemes. Community managed water supply scheme are the oldest forms of social organization [45].

\section{Major Problems in Community Water Supply Schemes in Nepal}

In the last two decades, there has been able to reach the number of positive progress in the right way at all stages of the water supply and sanitation project cycle. However there are several problems in community water schemes in Nepal, such as problem in sustainable functionality of completed water schemes with efficient operation and maintenance, upgrading the service level indicators in terms of quality, quantity, accessibility, and reliability [46] \& providing services to remaining un-served population, enhancing access to services to poor and marginalized, improving capacity at local levels, social and environmental safeguards [47]. The major problems and challenges, identified by various sector assessments, that need further action to institutionalize and firming up at all levels of 
service operations are discussed are further presented hereunder.

\subsection{Problem on Technical Approaches}

In urban water supply schemes, service delivery is poor and inadequate such as poor water supply coverage, low supply pressure, intermittent water supply, water is not portable without further treatment at the household level, non-revenue water is high and consumer satisfaction is low. Water supply provisions have largely been understood only for domestic demands for drinking, cooking, washing, and other personal hygiene. Other municipal uses such as water for firefighting, street cleaning, etc. and other institutional and industrial demand have not been understood as a service provider's responsibility. Local sources, especially in hills areas, are soon found to be inadequate to meet the demand for water supply for the rapidly and haphazardly growing towns and cities, equal access to basic water \& sanitation for squatters and slum dwellers, the poor and marginalized groups have largely been neglected [50].

Similarly, in rural water supply schemes, sustainable functionality has been found one of the major problems, and different studies have found that half of the completed water schemes are nonfunctional and need rehabilitation. With improved accessibility by roads and highway rural communities have emerged with nearby towns and markets, built services built to provide basic water and sanitation have been continuously inadequate. Mostly rural water supplies in hills are designed and operated based on a small surface and sub-surface sources with very marginal dry weather discharges \& such small sources are prone to dry out with the slightest change in climatic, geotechnical and vegetation of their catchment due to natural or human causes. Similarly, water source dispute is common among competing user communities in the absence of a scientific and comprehensive water resource planning at local levels.

\subsection{Problem on Gender Equity and Social Inclusion (GESI)}

The Government of Nepal has declared that so-called untouchability is illegal has created legal offense by law and act. However, untouchability still exists in many rural communities which creates barriers to menstruating, postnatal women, and disadvantageous group (DAG) Dalits from using family water points and toilet facilities is still a social taboo.

The water sector has focused mainly on gender issues, including increasing the involvement of women. More recently, particularly in Nepal, there has been a growing awareness that not all women and men benefit equally [48].

\subsection{Problem on Environmental Issues}

Global climate change has made water supply sources vulnerable to dry out causing water supply services inadequate or nonfunctional, especially water supply schemes designed and constructed based on small discharge sources.

The predicted changes in the hydrological cycle and the depletion of water resources are some of the major environmental challenges due to which Nepal is facing climate change impact on the drinking water supply system.
From the survey, it was perceived that there has a significant impact on climate change such as drying up of water sources, reduction of water discharge in springs [49].

Similarly, less emphasis on water source conservation, high deforestation \& pollution activities around the water source catchment area are other major problems on community water schemes. In the absence of adequate and effective sewerage and sanitation services, water sources in an urban and rural community have been polluted. The environmental consideration in the construction and operation of water supply and sanitation services has found largely ignored.

\subsection{Problems on Cost Recovery and Affordability}

The private sector and financial institutions are unable to invest in financially viable projects in the absence of a conducive cost recovery policy and legal provisions. Blanket application of a uniform cost recovery policy is leading low-income communities to choose lower service levels and traditional designs.

\subsection{Problems on Operation and Maintenance}

The poor quality of materials and workmanship mostly in the rural area has found higher operation and maintenance costs. In most water supply schemes, generally, revenue generated is inadequate due to low tariff, which is insufficient to pay staff salary, fuel or energy cost, chemicals for water treatment, maintenance, repair, and other costs. The preventative maintenance plan is less practice whereas corrective maintenance is generally taken place. Inadequate required skills of maintenance technicians in rural community water schemes are another problem. Generally, because of the inadequate fund with user committee, outsourcing of maintenance work is not commonly practiced and engaged locally available semiskilled technician for operation and maintenance.

\subsection{Problems on Institutional Issues}

It has found that there is still a lack of clarity on the roles and responsibilities between local government and other sector agencies for the development, operation, monitoring, and regulation of water supply and sanitation services. Because of the unavailability of skilled manpower and insufficient financial resources, local bodies have been unable to take responsibility for water supply services. Weak and ineffective coordination among various stakeholders, implementing agencies, service providers, and service regulator, there is high chances of resource duplication and wastage of effort.

\subsection{Problems on Legal Frameworks}

The existing water resource act of Nepal (WRA) 2004 was found insufficient and the water supply rules enforced under the existing water resource act. This WRA was realized to be inadequate to account for as broad and diverse socio-economic sector as water supply, draft WSSS policy 2014 was formulated. The parent law, the WRA, was 
primarily enforced to regulate water resource use for conservation and protection of surface water sources.

Similarly, water and sanitation sector stakeholder group meeting for sector efficiency improvement highlighted seven major issues in WASH in achieving the universal water and sanitation target for Nepal. These include (i) Sector Coordination, (ii) Institutional Framework and Capacity Building and Financing, (iii) Functionality, (iv) Sanitation and Hygiene, (v) Water Quality and (vi) Cross-cutting. Gender Equality and Social Inclusion, WASH in emergencies and monitoring and evaluation [50].

Furthermore, [51] has emphasizing (i) institutional fragmentation and limited sector coordination, (ii) financing and financial resource constraints, (iii) inadequate capacity in local authorities, (iv) lack of updated sector assessment and weak monitoring systems, (v) inadequate attention to water resource management and (vi) water quality and (vii) social exclusion of underprivileged groups including women towards effective water and sanitation service as the main problems that need to be addressed in Nepal to reach national goal underwater and sanitation.

Additionally, [52] has highlighted following problems related to community water supply and sanitation schemes in Nepal which is on World Bank experience in rural water supply and sanitation programs in Western Nepal (RWSSPWN); Poor management of water users and sanitation for operation and maintenance, resource mobilization and not addressing internal conflicts, resource misuse, and weak leadership. Similarly, Lack of access to management and technical skills and materials, Old schemes, the weak performance of agencies in planning, design, and implementation, external changes like demographic changes, disasters, climate change, and poor watershed management.

\subsection{Functionality of Water Supply Schemes}

Department of Water Supply and Sewerage has completed a lot of community-based water supply and sanitation projects as gravity, lifting, combined system (both lifting and gravity), solar system, rainwater harvesting, etc. in the country to fulfill the basic needs of people. According to the water supply and sanitation policy of the government of Nepal, projects are handed over to the water supply and sanitation users committee and the regular operation and maintenance is done by the users' committee. There are so many problems and challenges related to water supply and sanitation in the community managed project. The latest report published by the National management information project (NMIP) of the Department of water supply and sewerage (DWSS) shows the following functional status of water supply schemes.

The functional status of the completed projects was increasing in 2014 as compared to 2010 . However, there were still $38.5 \%$ nonfunctional water schemes in 2014 due to various problems [10].

Table (Table 7) presented herewith is functionality status of the water system and taps as per survey data conducted in 2014 by national management information project of the department of water supply and sewerage management.
Table 7. Situation of functionality of water supply schemes.

\begin{tabular}{lll}
\hline SN & Functionality of systems and tap & Systems \% \\
\hline 1 & Functionality of water supply scheme & \\
& Well-functioning & 25.4 \\
& Need minor repair & 36.1 \\
& Need major repair & 9.2 \\
& Need reconstruction & 8.6 \\
& Need rehabilitation & 19.8 \\
& Non-functional & 0.9 \\
& Providing water to all taps in the whole year & 68.2 \\
& Condition of water tap stands & \\
& Functioning, no need repair & 78.4 \\
& Need minor repair & 5.1 \\
& Need major repair & 16.5 \\
\hline
\end{tabular}

Source: [10].

\subsection{Functions / Serviceability of a Water Supply Service}

The serviceability of drinking water is said as good if the water is accessible, constantly available in sufficient quantity, and is potable. In Nepal, rural water supply and sanitation national strategy 2004 and national urban water supply and sanitation sector policy 2009 has clearly defined standard criteria for defining basic, medium, and high category of service level.

\section{Conclusions}

Drinking water is a basic need for survival and good health of human beings as well as for any form of life on earth. In the absence of potable and clean water, there is a high risk of transmission of serious diseases among people, like diarrhea, dysentery, cholera, and typhoid. Despite significant progress on community water schemes, in worldwide still, 2.2 billion people were out of access to safely manage water services.

The study found that about 829 thousand people are estimated to die each year from diarrhea because of unsafe drinking water, sanitation, and hand hygiene. In South Asia only, over 134 million people still do not have access to improved drinking water. Various studies have shown that progress on basic water supply in Nepal has reached up to $89 \%$, till the end of 2019. Community drinking water schemes in Nepal are facing various types of problems, such as technical problems, gender equity and social inclusion (GESI), cost recovery and affordability, operation and maintenance, institutional, and legal framework. Because of those problems on water schemes, there is always a high impact on un-functionality, poor service, and unsustainability, if problems are not timely and appropriately addressed.

\section{Acknowledgements}

We are very much thankful to Er. Prakash Upadhayaya, chairperson of LIAST, Prof. Dr. Narbikram Thapa, Mr. Pascal Gautam, friends, family, and all others for their direct and indirect supports in editing and finalization this research work. 


\section{References}

[1] WHO, "Safely managed drinking water - thematic report on drinking water," World Health Organization, 2017.

[2] S. Rout, "Rural Water Supply and Sanitation in South Asia: Problems, prospects and policy changes," 2010. [Online]. Available:

https://www.academia.edu/2545990/Rural_Water_Supply_and _Sanitation_in_South_Asia_Problems_Prospects_and_Policy_ Changes.

[3] SNV, "Open-defecation-free-Nepal-sanitation-healthdignity-and-development," September 2019. [Online]. Available: https://snv.org/update/open-defecation-free-nepal-sanitation-h ealth-dignity-and-development. [Accessed 2805 2020].

[4] NPC, "15th Plan (Fiscal Year 2076/77-2080/81)," Government of Nepal, National Planning Commission, Kathmandu Nepal, 2020.

[5] NLC, "Constitution of Nepal, Part 3, Fundamental Rights \& Dueties," $2020 . \quad$ [Online]. Available: http://www.lawcommission.gov.np/en/archives/981.

[6] UNICEF, "UNICEF's Strategy for WASH (2016-2030)," UNICEF, New Yor, 2016.

[7] WHO \& UNECEF, " Guidance on water and sanitation in extreme events," WHO \& UNECEF, 2010.

[8] WHO, "World Health Orginazation," 2020. [Online]. Available: https://www.who.int/news-room/fact-sheets/detail/drinking-w ater.

[9] D. B. Brooks, "Water Local level management," International Development Research Center,, Ottawa, Canada, 2002.

[10] WB, "Documents," 2013. [Online]. Available: http://documents.worldbank.org/curated/en/375231468124161 970/pdf/ICR15650P071280IC0disclosed03010130.pdf.

[11] RWSSP-WN, "Publications," 2018. [Online]. Available: https://www.rwsspwn.org.np/phase-ii-publications.

[12] ADB, "Report and recommendation of the president to the board of directors on a proposed loan to the kingdom of Nepal for the community based water supply and sanitation sector project," Asian Development Bank, 2003.

[13] DWSSM, "Water Supply Service Delivery Directives 2069 and Water Supply Service Manual - 2071," Department of Water Supply and Sewerage, Government of Nepal, Kathmandu Nepal, 2013.

[14] DWSS, "National Drinking Water Quality Standards, 2005," Government of Nepal, Ministry of Physical Planning and Works, Kathmandu, 2005.

[15] NMIP, "Nationwide coverage and functional status of water supply and sanitation status in Nepal," Department of Water Supply and Sewarage Management (DWSSM), Kathmandu, 2014.

[16] NPC, "Post disaster need assessment (PDNA)," National Planning Commission, Government of Nepal, Kathmandu, 2015.

[17] T. D. Acharya, S. Mainali, I. Yang and D. Lee, "ANALYSIS OF JURE LANDSLIDE DAM, SINDHUPALCHOWK USING
GIS AND REMOTE SENSING," The International Archives of the Photogrammetry, Remote Sensing and Spatial Information Sciences, Vols. Volume XLI-B6, pp. 201-203, 2016.

[18] M. Coffta, "Litrature review," 2020. [Online]. Available: https://guides.library.bloomu.edu/litreview. [Accessed $7 \quad 6$ 2020].

[19] AGDH, "For Consumer," 2010. [Online]. Available: https://wwwl.health.gov.au/internet/publications/publishing.n sf/Content/ohp-enhealth-manual-atsi-cnt-1 ohp-enhealth-man ual-atsi-cnt-1-ch6 ohp-enhealth-manual-atsi-cnt-1-ch6.1 . [Accessed 96 2020].

[20] MoPPW, "Nepal Law Commission," Ministry of Physical Planning and Works, Government of Nepal, 2009. [Online]. Available:

http://www.lawcommission.gov.np/en/wp-content/uploads/201 9/12/National-Urban-Water-Supply-and-Sanitation-Sector-Pol icy.pdf. [Accessed 76 2020].

[21] MoWS, "Ministry of Water Supply, (MoWS), Nepal," 2020. [Online]. Available: https://mows.gov.np/812/?lang=en.

[22] Swiss Red Cross, Water and sanitation guidelines, Rainmattstrasse, Berne: Swiss Red Cross, 2014.

[23] R. K. GC, S. Ranganathan and R. P. Hall, "Does Rural Water System Design Matter? A Study of Productive Use of Water in Rural Nepal," Water, MDPI, pp. 1-20, 2019.

[24] GoN, "National Urban Water Supply and Sanitation Sector Policy,", Government of Nepal, Kathmandu, 2009.

[25] iDE Nepal, ICIMOD, "Natural Resource Management Approaches and Technologies in Nepal: Approach - A multiple-use water system," ICIMOD, Kathmandu, Nepal, 2013.

[26] MoWSS, "Nepal WASH sector development plan (2016-2030)," MoWSS, Sector efficiency improvement unit, Kathmandu, Nepal, 2016.

[27] CDC \& USAID, "Preventing Diarrheal Disease in Developing Countries: Safe Storage of Drinking Water," Center for diseases control and prevention (CDC) and United States Agency for International Development (USAID), From the American people, Arlington, VA 22209, USA, 2009.

[28] CAWST, Wellness through water An introduction to household water treatment and storage, Calgary Alberta, Canada: Center for affordable water and sanitation technology, 2009.

[29] R. Kumar, Water supply engineering, Delhi, India: Aitabs publishers, India, 2016.

[30] EPA, "Point-of-Use or Point-ofEntry Treatment Options for small drinking water supply system," Environmental Protection Agency, United States, 2006.

[31] B. Stauffer and D. Spuhler, "Affordable solutions for viable sanitation and water management," 2019. [Online]. Available: https://sswm.info/about-toolbox.

[32] CAWST, "An Introduction to Household Water Treatment and Safe Storage, A CAWST Training Manual," Centre for Affordable Water and Sanitation Technology (CAWST), Calgary, 2009.

[33] UNISDR, "Terminology on Disaster Risk Reduction," United Nations International Strategy for Disaster Reduction, Geneva, 2009. 
[34] MoUD, "Water safety plan handbook," Ministry of urban development, Government of Nepal, Kathmandu, Nepal, 2013.

[35] WHO, "Global status report on water safety plans: A review of proactive risk assessment and risk management practices to ensure the safety of drinking water," World Health Organization, Geneva, 2017.

[36] USCG, "USGC, Science for a changing world," 2020. [Online] Available:

https://www.usgs.gov/special-topic/water-science-school/scien ce/where-earths-water?qt-science center objects=0\#qt-scienc e_center_objects. [Accessed $240 \overline{5}$ 2020].

[37] The UN, "The Sustainable Development Goals Report 2019," The United Nations, New York, 2019.

[38] WVI, "Clean water," 2020. [Online]. Available: https://www.worldvision.org/our-work/clean-water.

[39] UN, "Transforming our World: The 2030 Agenda for Sustainable Development," 2015. [Online]. Available: https://sustainabledevelopment.un.org/post2015/transformingo urworld/publication.

[40] WHO, "Safely managed drinking water - thematic report on drinking water," World Health Organization, Geneva, Switzerland, 2017.

[41] WHO, "Vision 2030: The resilience of water supply and sanitation in the face of climate change," World Health Organization, Geneva, 2009.

[42] UNICEF, "Unicef South Asia," 2020. [Online]. Available: https://www.unicef.org/rosa/water-sanitation-and-hygiene-was h. [Accessed 2505 2020]

[43] Unicef/WHO, "Drinking Water Equity, Safety and Sustainability: Thematic report on drinking water 2011," WHO/UNICEF Joint Monitoring Programme for Water Supply and Sanitation (JMP), United States of America, 2011.
[44] MoHA, "National Strategy for Disaster Risk Management in Nepal," Ministry of Home Affairs, Nepal, Kathmandu, 2009.

[45] DWSSM, "About us: Introduction to DWSSM," 2020. [Online]. Available: https://dwssm.gov.np/en/introduction.

[46] NMIP, "National Wide Coverage and Functionality of water supply and sanitation in Nepal," National Management and Information Project, GoN, DWSS, Kathmandu Nepal, 2014.

[47] NPC, "Sustainable Development Goals, 2016-2030 National (Preliminary) Report," Government of Nepal, National Planning Commission, Kathmandu, Nepal, 2015.

[48] DWSSM, "Sanitation Status of Nepal Factsheet," Department of Water Supply and Sewarage Management, Kathmandu, 2018.

[49] DWSS/WHO, "Water Safety Plan Handbook," Kathmandu, GoN, MoUD, Department of Water Supply and Sewerage Management, 2013, p. 4.

[50] MoUD, "National Water Supply and Sanitation Sector Policy 2014 (Draft)," GoN, Ministry of Urban Development, Kathmandu, 2014.

[51] DoLIDAR, "HRBA \& GESI STRATEGY \& ACTION PLAN Operationalizing Human Rights-Based Approach (HRBA) and Gender Equality \& Social Inclusion (GESI) Principles in the Water and Sanitation Sector," Department of Local Infrastructure Development and Agricultural Road, Kathmandu, Nepal, 2015.

[52] R. Bashyal, "Climate tracker," 2017. [Online]. Available: http://climatetracker.org/climate-change-impacts-water-resour ces-case-nepal/\#: :text=In $\% 20 \mathrm{Nepal} \% 2 \mathrm{C} \% 20$ climate $\% 20$ cha nge $\% 20$ has,food $\% 20$ store $\% 20$ areas $\% 20$ of $\% 20$ Nepal. 